\title{
Open Dynamic Situations of Classroom Use of Digital Technologies: Investigating Teachers' Interventions
}

\author{
Maha Abboud $^{1,2}$ (D) $\cdot$ Janine Rogalski $^{1,2}$
}

Accepted: 4 May 2021 / Published online: 8 June 2021

(C) Ontario Institute for Studies in Education (OISE) 2021

\begin{abstract}
This study addresses teachers' activity when working with digital technologies (DT) in their classrooms. We build upon a model that considers teaching as managing open dynamic situations. Within the model, teachers' activity is viewed as diagnosing students' mathematical activity, managing uncertainties due to the characteristics of the situation and decision-making about didactic interventions. The study extends our earlier work and focuses on teachers' interventions in DT-based lessons, as they manage disturbances caused by unexpected difficulties. Our first observation is that there is a substantial change in how teachers diagnose these difficulties compared to paper-and-pencil environments. Notably, they need to make more inferences about the pedagogical support that is provided. Second, we show that in such conditions, rather than facing the single dynamicity of the class as a whole, the teacher has to deal with multiple, open dynamic situations (small groups named mini-classes), which are themselves intertwined in the dynamics of students' interactions with technology. Moreover, even if teachers are able to make reliable inferences concerning an individual student's current difficulties, they must also be able to make inferences about the scope of such difficulties within the class as a whole. We present four case studies that illustrate the diverse approaches that teachers take when managing such open dynamic situations and use them to illustrate the concepts and analytical tools that are introduced.
\end{abstract}

Résumé Dans cette étude, nous abordons les pratiques des enseignants qui utilisent les technologies numériques (TN) dans leurs salles de classe. Nous en élaborons un modèle qui conçoit l'enseignement comme une activité de gestion de situations dynamiques ouvertes. Au sein du modèle, la pratique de l'enseignement est vue comme une activité qui exige de poser un diagnostic sur les activités mathématiques des élèves, qui demande aussi de gérer les incertitudes selon les caractéristiques inhérentes à la situation et de prendre des décisions en matière d'interventions didactiques. Cette analyse constitue

Maha Abboud

Maha.abboud-blanchard@u-cergy.fr

1 LDAR, CY Cergy Paris Université, 95000 Cergy, France

2 Université de Paris, 75013 Paris, France 
un prolongement d'une de nos études antérieures et elle se penche sur les interventions des enseignants quand ils donnent des cours fondés sur les TN et qu'ils doivent composer avec les perturbations amenées par des difficultés imprévues rencontrées. Nous constatons d'abord un changement important dans la façon qu'ont les enseignants d'évaluer ces difficultés en comparaison avec le diagnostic qu'ils poseraient dans un environnement papier-crayon. Notamment, ils doivent faire plus d'inférences concernant le soutien pédagogique fourni. Deuxièmement, nous démontrons que dans de telles conditions, plutôt que de faire face, dans son ensemble à une seule dynamique de classe, l'enseignant doit composer avec de multiples situations dynamiques ouvertes (des petits groupes appelés mini classes), qui sont elles-mêmes inextricablement liées aux dynamiques émanant d'interactions entre les élèves et la technologie. De plus, même si les enseignants sont capables de faire les bonnes déductions quant aux problèmes actuels rencontrés par un élève, ils doivent de même être capables d'évaluer la portée qu'ont ces difficultés dans l'ensemble de la classe. Nous présentons quatre études de cas qui illustrent les diverses approches adoptées par les enseignants pour gérer les situations dynamiques ouvertes et qui font valoir les concepts et les outils analytiques présentés.

Keywords Mathematics $\cdot$ Technology $\cdot$ Dynamic situations $\cdot$ Teacher activity $\cdot$ Teacher interventions $\cdot$ Teacher-student interactions

\section{Introduction}

Several studies of mathematics education have investigated teachers' practices when using digital technologies (DT) and proposed various frameworks to examine different features of these practices (Monaghan, 2004; Ruthven, 2014; Clark-Wilson et al., 2014a, b). Our own earlier work (Abboud-Blanchard, 2014; Abboud \& Rogalski, 2017) has contributed to this research movement. We sought to better understand the integration of DT into day-to-day mathematics classrooms, by analyzing the "pragmatic" dimension of teachers' activities. In the present paper, we develop our analysis and shed light on teachers' ability to anticipate students' conceptual difficulties. We adopt a fine-grained approach to analyze teachers' interventions when students are working individually or in small groups on DT tasks (i.e. tasks that are expressed in, and should be performed through, a DT-based environment). The goal is to better understand how teachers diagnose and respond to students' difficulties. Analyzing the teacher's diagnosing strategies provides an insight into the means they use to develop students' understanding of mathematical concepts and procedures and, possibly the missed opportunities for supporting effective students' development.

A general approach to teachers' activities was developed in the early 2000 s that considers teaching as managing an open dynamic situation (Rogalski, 2003). Students' activities in the classroom have their own dynamics, which are a function of the relationship between the task and their mathematical learning. Their actions, and how they understand the task they are asked to undertake, determine if they are progressing, or not. Within this approach, the teachers diagnose their students' mathematical activities and make decision about didactic interventions - either immediate or delayed — and control their effects on students. The initial framework was later extended to take into account the specificities of teachers' use of DT-based tasks in the classroom and consider tensions and disturbances in students' intended cognitive route (Abboud et al., 2018). The approach considers both the teacher's goals when anticipating his/her students' activities and the adaptations that take place during their actual implementation. In particular, it directs attention to the management of uncertainties that are inherent in DT environments. To provide effective assistance, teachers have to diagnose the current state of their students' activities, their progress towards accomplishing the task, any obstacles they are encountering (and possible dead ends) and identify didactic actions that could foster students' learning. However, there is a tension between the need for adaptation —involving "emergent goals" (Monaghan, 2004) — and the fact that the 
goal of action is "the decisive regulation instance"-as Hacker (1985, pp. 74-78) stressed when discussing human action. Moreover, several of the studies cited above have highlighted that, when working with DT, teachers face substantial changes in the conditions that usually help them to identify students' difficulties. On the one hand, students may struggle not only with mathematical notions, but also with instrumental manipulations and, possibly, with specific problems related to how the technology impacts mathematical objects. On the other hand, indications of students' activities are more often labile, which puts high demands on the teachers' diagnosis skills (Drijvers et al., 2010).

The aim of this paper is to present analytical concepts and tools that make it possible to identify how teachers diagnose success, or the difficulties that students encounter when working with DT, ${ }^{1}$ notably in computer labs, and how they can be used to enhance mathematical activity and learning in this context. Four vignettes of teachers' interventions and teacher-student interactions are presented that illustrate the corresponding analyses. One practical concern is to offer ideas that can be applied in teacher education, in order to tackle the ongoing problem of the low integration of DT into the mathematics classroom.

\section{Previous Outcomes and Theoretical Background}

The classroom environments that we examine are often used in secondary teaching in France, where students use the computer lab for their DT-based mathematics lessons. While other environments have been developed over the past 10 years, with the spread of laptops and digital tablets, they remain insufficient in schools as they rely on the provision of equipment and funding from institutional sources. ${ }^{2}$ The DT-based lessons we study concern the use of technologies in mathematics teaching that resemble those described by Monaghan (2004). In broad terms, the teacher presents a short introduction to the task; a worksheet directs students' activity; then, the teacher moves around the class ensuring that everyone is working and helping with any mathematical or technical issues. Abboud-Blanchard and Paries (2008) showed that students in a computer room generally work together in small groups. So, after a brief initial introduction to the task, the class splits into several mini-classes (one or two students per computer) that the teacher interacts with separately. Unlike paper-and-pencil lessons, where students must often adapt to the teacher's planned path, in this scenario, the teacher adapts to each mini-class and its current level of understanding (Abboud-Blanchard, 2014). This important characteristic of class management in a technology-based lesson differentiates it from the non-technology situation. Monaghan (2004) pointed out this difference, noting that teachers tend to spend more time talking to small groups of students around a computer, and less time talking to the class as a whole. An immediate consequence of this phenomenon is that teachers often lack time to accomplish their intended goals. In addition, it introduces uncertainties about the relevance of collective interventions: rather than facing the single dynamic of the classroom as a whole, the teacher faces multiple, open dynamic situations that are, in turn, intertwined in the dynamics of students' interactions with the technology.

Other research into the teacher's role when working with small groups has highlighted several features that are found in DT environments, notably the fact that it is impossible for teachers to keep track of each group's work (Dekker \& Elshout-Mohr, 2004). The focus is often on monitoring group work, providing assistance and facilitating collaboration (Tabach \& Schwarz, 2017). Teachers have thus to adapt their interventions to their students' needs and first identify any difficulties before providing guidance. Focusing on the role of the teacher as a monitor and guide for students' group activities, Hofmann and

\footnotetext{
1 The digital technologies referred to in this text are commonly used in French secondary school mathematics, such as dynamic geometry, online exercises, or spreadsheets.

2 Please note that this article presents a study that was carried out before the COVID-19 pandemic. The crisis has led institutions to review their priorities in terms of equipping students and teachers.
} 
Mercel (2016) explored the variety of strategies that teachers use to encourage students to express and discuss their ideas. Among them, the "inviting to speak" strategy (pp. 411-412) is one way to initiate interactions with the group; it is an opportunity for the teacher to discover the difficulties their students are facing and develop contingent responses. This strategy is often observed when DT mediates the student's activity. In this situation, the teacher needs to ask the student about the procedure they used, and any feedback that is provided by the machine, because looking at the screen is not always enough to understand what the student has already done (Abboud-Blanchard, 2014).

Another concept that is used when investigating teachers' activity within DT environments is that of emergent goals, which is found in Monaghan's approach (Monaghan, 2004). This concept helps to identify and interpret phenomena that occur when there are discrepancies between what the teacher was expecting to happen, and what happens in reality, especially when the students' activity differs from the intended cognitive route. Lagrange and Ozdemir (2009) used the concept to analyze situations encountered by experienced teachers and found that they are marked by uncertainty and improvisation. It is consistent with the model that sees teachers' activity as managing open dynamic situations (Robert \& Rogalski, 2005).

\section{Theoretical Frame and Methods}

The overarching theoretical framework for our current and previous studies is the double approach. This framework was initially developed by Robert and Rogalski $(2002,2005)$ and has been continually extended by French mathematics didacticians (see Abboud-Blanchard et al., 2017). It is based on an adaptation of Leontiev's Activity Theory developed in cognitive ergonomics (Leplat, 1997). It considers that the main object of the teacher's activity is students' mathematical learning. To this end, teachers design cognitive routes that consist of a succession of tasks (the cognitive dimension), and then act as mediators, helping students to complete the task (the mediative ${ }^{3}$ dimension) (Robert $\&$ Rogalski, 2005). In the case of teachers designing and implementing DT-based tasks, Abboud-Blanchard (2014) has shown that a pragmatic dimension must also be taken into account when analyzing their activity.

Based on prior work (Rogalski, 2003), Abboud and Rogalski (2017) considered the teacher's activity as a case of managing an open dynamic situation ${ }^{4}$ made up of students' activities in the classroom and their mathematical learning. The concept of "dynamic" is twofold. On the one hand, what happens in the classroom is determined not only by the teacher's actions, but also by his/her students' current activities. On the other hand, medium- or long-term learning (and its limits or absence) does not depend simply on the teacher's practices, but also on what students do outside the classroom (e.g. homework), and their interactions with external resources (including the Internet). "Open" relates to the fact that there are (in general) few, if any, models to diagnose students' activities and learning: the teacher has to identify them and often has also to develop and implement on-thespot actions to help students understand and complete tasks they are set. ${ }^{5}$ The presence of DT in the classroom brings new challenges. From the diagnosis point of view, teachers have to determine the

\footnotetext{
3 The term "mediative" refers to the fact that the teacher provides a mediation between the students and the mathematical content (Robert \& Rogalski, 2005, p. 272).

4 This terminology may vary, for example, the terms dynamic environment, dynamic system, dynamic context, and dynamic situation are used. Roditi (2011) expressed the idea of teachers managing a dynamic system as follows, "teachers intervene in the student-knowledge's dynamics" (p. 49) and "interactions are not only determined by the teacher and students, they also have their own dynamics" (p. 60).

${ }^{5}$ In other approaches, openness may be expressed as unpredictability. For example, in the context of technical control processes, Lundberg and Johansson (2020) state that there is an element of unpredictability in dynamic systems which "means that we cannot accurately anticipate which information will be relevant for each step in a process" (p. 16).
} 
mathematical content to be learned, their students' knowledge about the device and its procedures and, if relevant, the impact of the computational transposition (Balacheff, 1994) on mathematical objects. Teachers are often aware of the uncertainty in their diagnosis and the need to use inferences when selecting the appropriate didactic support. The consequence of an inadequate diagnosis is that their intervention falls outside the student's Zone of Proximal Development (Vygotsky, 1978) and may hamper their work rather than supporting it.

Expanding on this picture of DT-based lessons, and building on the theoretical elements outlined above, the present study seeks to characterize how teachers diagnose their students' difficulties and examine to what extent their support meets their students' needs. Our methods draw upon theoretical concepts and tools that are presented in detail in our earlier work (Abboud \& Rogalski, 2017; Abboud et al., 2018), which we briefly recall here.

Tension and Disturbances. Tension and disturbances focus on the relationship between lesson preparation (anticipation) and its actual implementation (adaptation). Tensions are manifestations of the teacher's struggle to maintain the intended cognitive route and adapt to phenomena linked to class dynamics. Some of these tensions can be predicted by the teacher who can plan how to manage them. Others are unexpected, and teachers must make in situ decisions that direct their ongoing activity. Tensions can be analyzed along three dimensions (see Abboud-Blanchard, 2014): temporal, cognitive and pragmatic. Disturbances are the consequences of unmanaged or poorly managed tensions that lead to a significant deviation from the planned cognitive route, or even an exit from it. They happen when a new issue emerges and is managed while, at the same time, the current issue is not fully addressed, or when the new issue departs from the initial cognitive route.

We used this theoretical construct in our earlier work to identify tensions, and their management, in the teacher's activity. Our current work develops a dimension of tensions that has been overlooked: the conceptual dimension. This tension, and its resulting disturbance, is related to students" "deep" misconceptions; especially when the teacher is unaware of the problem, as it should have been overcome at an earlier stage of learning (previous school years).

Types of Teachers' Aids. In paper-and-pencil environments, Robert and Hache (2013) defined two types of teacher's aids. "Procedural" aids correspond to the teacher indicating, either directly or indirectly, a procedure to be followed, a theorem to be used, etc. "Constructive" aids correspond to the teacher building on students' work by identifying what could be generalized, or referring to general concepts that have already been learned. By extending this typology to DT-based environments, we can take into account the instrumental nature of the aid. We distinguish between "handling" instrumental aids which refer to the use of software, without making a link to the associated mathematical content, and "mathematical" instrumental aids, which relate the instrument to mathematics. By applying the procedural/constructive distinction to the two types of instrumental aids, we define four types. A fifth type, "inter-instrumental" aid, occurs when the teacher asks students to say, do or remember what they would have done in another, more familiar environment.

We use this typology in our current study with a focus on the relationship between the teacher's diagnosis, the various aids they choose to adopt and their effectiveness.

In the following section, we present four case studies. These examples illustrate our analyses and findings regarding how teachers organize their work with students in DT environments, how they diagnose and provide aids and succeed (or not) in improving their students' cognitive path. This finegrained analysis aims to identify how teachers implement both planned and on-the-spot decisions. 
It can be seen as a complement to quantitative research on the impact of DT use, presented in the recent review by Drijvers (2018).

\section{Case Studies}

Data are derived from series of observations of mathematics lessons that were conducted in the context of an empirical research project that investigated the "ordinary" practices of "ordinary" mathematics teachers (i.e. those who were not part of any research project). They concern experienced teachers who often use DT, although with a critical eye. Lessons involved 8th to 10th grade classes at lower and upper secondary level (students aged 13-16 years). They were run in computer labs rather than regular classrooms equipped with mobile devices, such as laptops or tablets.

Data gathering methods sought to reduce, as far as possible, the impact of researchers (observers) on teachers' and students' activities. Hence, the analyzed sessions were chosen and recorded by the teachers themselves ${ }^{6}$. All video recordings were transcribed in full. The first step was to view the videos in order to gain an initial, broad overview of individual interventions, the management of small groups and any collective interventions. In a second step, transcripts were analyzed as a set of episodes. An episode began when the teacher joined a group and interacted with it (whether the interaction was initiated by students or the teacher), and ended when he/she moved on to another group.

Some of these case studies are presented in our earlier papers to illustrate other aspects of our investigation using the open dynamic situations model. In the current paper, we present particular episodes that illustrate the teachers' activity when diagnosing their students' mathematical activity, and the decisions they make about didactic interventions. In each case, we first briefly describe the teacher's profile and the goal of the observed lesson (with a presentation or screenshot of the mathematics problem that students were asked to solve), and then focus on the specific feature that it highlights.

\section{Mary: When Misunderstandings Prevail over the Diagnosis}

Mary $^{7}$ is an experienced upper secondary level teacher (10th to 12th grade), with extensive experience of personal computer use, and average experience of using it as a teaching tool. She considers that using DT requires knowing and mastering the tools, and focuses on using them to meet specific teaching targets.

The student, Lisa, is studious. The teacher-student interactions reported here took place during the second session of a lesson in which the goal was to revise concepts related to numerical functions (which were first encountered in the previous academic year). Mary guided her students in the use of GeoGebra (geometric and graphical constructions and spreadsheets) (Fig. 1) using a worksheet that she provided at the beginning of the session. The use of GeoGebra aims to help students to explore the problem, i.e. to examine the area of the rectangle MNPB for different positions of the point M.

This case highlights tensions that affect the teacher's activity, in particular, diagnosing the student's difficulty and making progress towards the intended goal.

\section{A persistent misunderstanding of the purpose of the task in GeoGebra}

A local misunderstanding of the goal of the task appears at the beginning of the interaction. The student, Lisa, is focused on what she sees on the screen (a rectangle inside a triangle) and understands

\footnotetext{
${ }^{6}$ Teachers were later interviewed, and their preparatory documents were collected, in order to gain an insight into their profiles and goals, and interpret the choices they had made when preparing for, and during the lesson.

7 Both teachers and students are anonymized throughout the current paper.
} 


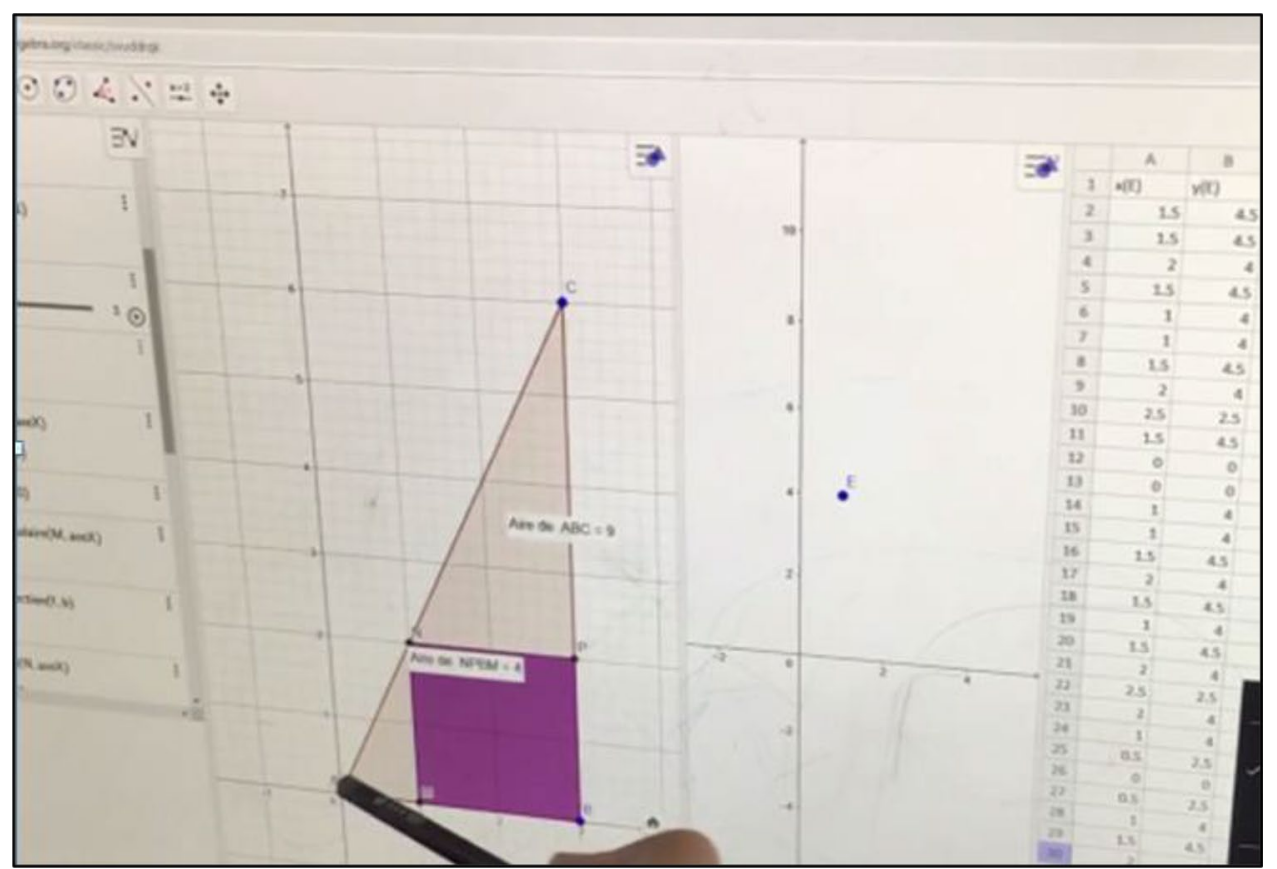

Fig. 1 A screenshot of Lisa's screen at the beginning of the observed interaction. The problem statement is as follows: $\mathrm{ABC}$ is a right-angled triangle in $\mathrm{B}$ with $\mathrm{AB}=3$ and $\mathrm{BC}=6 . \mathrm{M}$ is a variable point on $[\mathrm{AB}] . \mathrm{N}$ is a point on $[\mathrm{AC}]$ and $\mathrm{P}$ on $[\mathrm{BC}]$, such that MNPB is a rectangle. Can you find positions of $\mathrm{M}$ such that the area of the rectangle MNPB is equal to half the area of the triangle $\mathrm{ABC}$ ?

the rectangle height $\mathrm{MN}$ as the $y$-coordinate, while the teacher, Mary, considers that the $y$-coordinate corresponds to the value of the area of the rectangle AMNB, and is a function of AM.

7. Mary: $[\ldots]$ it's a line in what frame?

8. Lisa: in a representation

9. Mary: graphical?

10. Lisa: graphical

11. Mary: graphical ... of what?

12. Lisa: [remains silent]

13. Mary: a graphical representation of what?

14. Lisa: well, of a curve

15. Mary: of a function!

16. Lisa: of a function, sorry.

The misunderstanding continues, as shown by the interaction below.

27. Mary: OK! Where could you associate this area value with a $y$-coordinate?

28. Lisa: $\mathrm{mm}$... MN [gestures to a vertical line, Lisa puts her pen parallel to this line]

29. Mary: where on your, ... your... /Lisa: ah, er;/ Mary: on your computer

30. Lisa: here

31. Mary: on your computer [insists on this word]

32. Lisa: ah...

33. Mary: Why am I asking you this question? 
34. Lisa: I don't know

Mary's last tentative question about the goal of the task similarly failed:

45. Mary: what are you asked to compute each time?

46. Lisa: er... I don't know.

47. Mary: in the end, this exercise, what is it showing you?

48. Lisa: it shows me that I can get a function from geometry.

Lisa is completely focused on local sub-tasks, while Mary is following the intended cognitive route, which seeks to help the student to understand transitions between a function's frames of representation.

\section{Tension Between Diagnosing Lisa's Misconception (About the y-Coordinate) and Making Progress} Towards the Final Goal

Here, we see that Lisa's misconception of the $y$-coordinate ${ }^{8}$ as a line and not a value was an obstacle to her understanding of the task. In the French curriculum, this notion is introduced at grade 8 and is used in various tasks in grade 9; Mary did not expect it to be a problem for a grade 10 student.

1. Mary: what is bothering you?

2. Lisa: it's that the $y$-coordinate is a square instead of being a line

3. Mary: because the $y$-coordinate is a line?

4. Lisa: yes, it's a line, perpendicular to the $x$-axis

At this point, Mary moves on from the interaction about the $y$-coordinate (which was bothering Lisa) and returns to her initial goal: identifying different representations of functions in a GeoGebra context. However, several interactions later, the same difficulty reappeared:

27. Mary: OK! Where could one possibly associate this area value with a $y$-coordinate?

28. Lisa: $\mathrm{mm}$... MN [gestures to a vertical line, Lisa puts her pen parallel to this line]

Mary was fully focused on guiding Lisa, using instrumental procedural aids, toward considering the area of the rectangle as a function of the $x$-coordinate of $\mathrm{M}$-i.e. as a $y$-coordinate-while Lisa could not think of the $y$-coordinate as anything other than a vertical line. Lisa's misconception hindered her understanding of Mary's explanations about the representation of the function by the trace command (in GeoGebra):

70. Lisa: but, there's no trace ... there should be ...

71. Mary: why?

72. Lisa: I don't know, there must be a trace, I can see it [in the context menu]

73. Mary: yeah, display the trace

74. Lisa: [manipulates ...]

75. Mary: no but it's OK, what did you want to do?

76. Lisa: I wanted a line

77. Mary: a line? To do what?

${ }_{8}^{8}$ In French the $y$-coordinate is termed the ordonnée and the term ' $y$ ' is not used. 
78. Lisa: to trace the line(s)

At the end of this episode, we observe that the teacher tries to speed up the pace in order to manage the temporal tension of which she is now aware of. As soon as Lisa talks about a function, Mary validates her statement ("that's it, that's it, we're there [laughs]"). Here, the teacher needed to believe that her student has advanced towards (even if she has not yet reached) the targeted goal (at least she's on the right path) in order to be able to continue her cognitive route with the remainder of the class.

\section{Daisy: When Supposed Outdated Notions Interfere in Diagnosing and Managing}

The observations from Daisy's class relate to the use of Online Exercise-Bases with grade 10 students. Daisy is very experienced and has been teaching for over 15 years. She is familiar with the use of different technologies in the classroom and had a thorough understanding of the online technology she was using. She was very clear about the exercises she set for her students and the aids provided by the software application. One of her goals was that students should interact with their computers with little assistance from her, in order to help them acquire problem-solving techniques and tackle exercises autonomously.

She planned to begin by explaining the activity to her students, then move around the classroom supporting them with collective or individual interventions, if necessary. In fact, of her 40 interventions, only seven were collective, and mainly aimed to set up her students with what they needed to undertake the task.

Daisy's case highlights the management of an unexpected, major difficulty that created cognitive and temporal tensions in the teacher's activity. She responded by focusing on giving constructive aids (not necessarily related to the use of DT), considering that procedural aids would be provided by the software. Two days after the session, she stated: "I really thought that they would be able to do at least the first five exercises, but it was not the case. In fact, I gave the same exercises to another class and those students were faster." This case also illustrates the difficulty she had in shifting from providing individual to collective assistance.

Students were set a series of exercises that they were expected to solve with an online tool. These exercises required them to recognize, graphically, the image or pre-image of points on curves (Fig. 2).

Several students found it difficult to grasp the notions of image and pre-image, ${ }^{9}$ which were at the core of the planned tasks; Daisy had not anticipated this difficulty. Several times, she provided in response mathematical aids that were not directly related to the use of DT. For example, after asking for help, a student (Robin) says:

Robin: the image, is it the $x$-axis or $y$-axis?

Daisy: when it says -4 has 3 as image by the function $f$ ?

Robin: I search for the pre-image.

Daisy: it doesn't say pre-image, it says image, don't confuse things

Robin: I do $f(-4)$

Daisy: go on!

Other students also did not understand the link between the two notions - or that the point was on the curve representing the function. This is illustrated by the exchange that followed Tom's request for help:

Daisy: so, -1 has 1 as pre-image using the function? So, here, do you think it corresponds? 1 has the image -1 and you write: the point $(-1,1)$ is on the curve representing $f$ ? The coordinates of points on the curve are $x$ and?

${ }^{9}$ In French, the pre-image is termed the antecedent. 


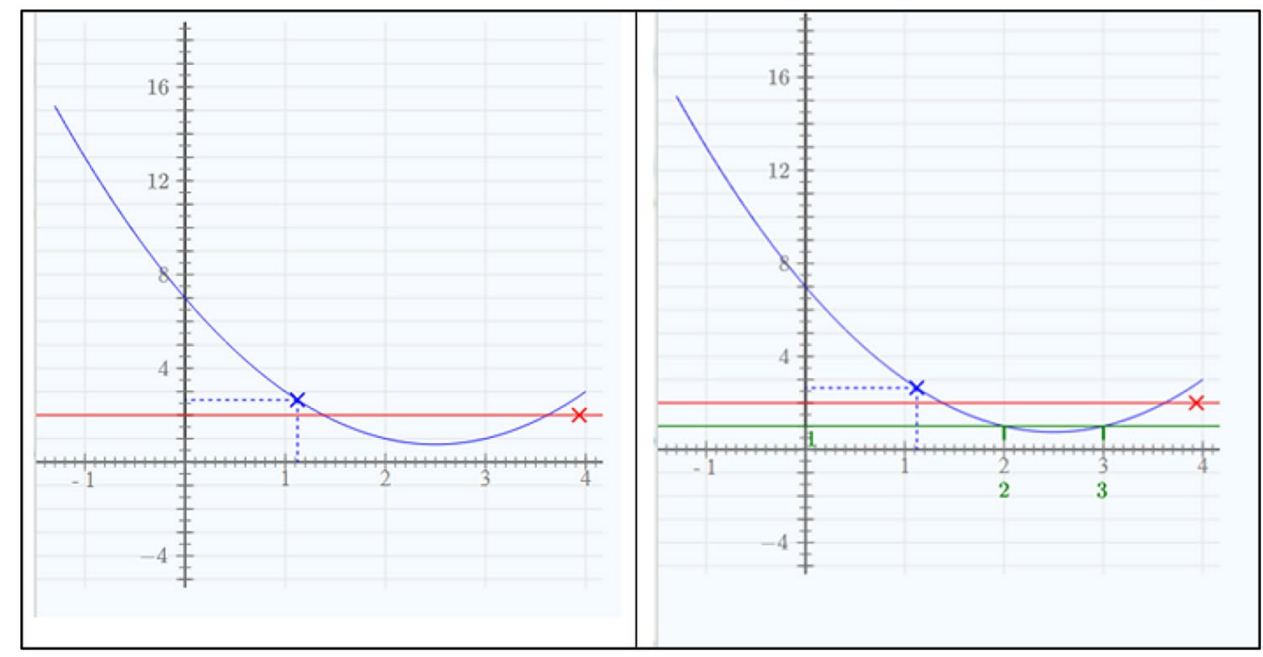

Fig. 2 Example of an exercise that the student may encounter (left) and the corresponding help that the application can provide (right)

Tom: $y$

Daisy: yes, but $y$ is replaced by? When you use the function $f$ ?

Tom: er...

Daisy: $(x, f(x))$.

Tom: so, it's $(1,-1)$.

Daisy: OK!

Others students only searched for one pre-image (as for the image) and did not explore the possibility that there might be several; the software returned an error message. The following extract illustrates the case of a student who asked for help:

Daisy: are you sure that there is only one pre-image? Here's where you're going wrong!

The same situation was observed for another student, Tony:

Daisy: you put one pre-image and not several?

Tony: yes, I failed.

Daisy: pay attention, you're not reading the pre-images but the images.

Tony: when we read the pre-images, is that the $y$-axis?

Daisy: no, you're reading them on the $x$-axis, you didn't do that.

In a more complex exercise, students also found it difficult to use the software to help them read both the $x$ - and $y$-coordinates of points on the curve representing the function. In their search to identify the image and pre-image, students confused the two notions. To help them, Daisy drew upon the paper-andpencil work they were familiar with. The strategy was not always efficient, particularly if students were unclear about the status of images and pre-images, and Daisy had to guide them during task performing.

Overall, Daisy tended to use constructive aids to help individual students. For procedural issues, she asked them to consult the help provided by the software application. This case illustrates the potential of the software to determine some of the teacher's actions.

Daisy did not take the opportunity to make a collective intervention with her students and go over the basic notions of images and pre-images. One reason could be that she did not want to disturb other 
students who were not in difficulty. It is possible that she considered that the notion had been understood, as she said to one student: "we've already seen that, you know it", and that the students' problems were related to minor procedural errors rather than a misconception.

\section{Clara: When Students' Difficulties in Switching from Paper-and-Pencil to DT Environments Become the Core of the Diagnosis}

Clara is an experienced secondary school mathematics teacher. She is not an expert in technology, but she supports its use in mathematics education, and runs DT classes with her students. The lesson presented here reports on the use of GeoGebra with an $8^{\text {th }}$ grade class. Students were asked to, successively, draw a segment $A B$, the circle with $A B$ as its diameter, a point $M$ on the circle, and to drag $M$ in order to make a conjecture about the value of the angle AMB. Clara's goal was that her students first observe that $\mathrm{AMB}$ is a right-angled triangle at $\mathrm{M}$, and then prove it.

This case shows that teachers can find it difficult to predict some of the obstacles that may arise when switching from the paper-and-pencil environment to the same tasks in the DT environment (an effect of the computational transposition defined by Balacheff (1994)). When diagnosing this obstacle in situ, Clara considers that it is up to her to make the link between the two environments, in order to ensure that her lesson will run as planned. Consequently, the teacher plays close attention, via procedural and inter-instrumental aids, to guiding her students through the correct method to carry out the sub-task that caused the obstacle. However, she faced several unforeseen tensions that were created by the fact that her students' mathematical activities were mediated by the software. These tensions run throughout the lesson, disrupt the cognitive route, and the teacher's aim of getting her students to prove the conjecture fails. Here, we present two illustrative tensions.

The first difficulty students encountered was to draw the circle. The segment AB (diameter) had already been drawn in the first step. Most students found this task difficult-some drew a circle with centre A (or B) and radius AB, others drew a circle and then placed the two points, A and B, on it (as they could have done in a paper-and-pencil environment). As Clara diagnosed these difficulties (10 min after the session started), she began giving individual inter-instrumental aid by referring to the paperand-pencil environment:

Clara: how do you draw a circle with diameter $\mathrm{AB}$ with paper-and-pencil?

Sarah: I draw the midpoint of AB.

Clara: yes, that's right!

Realizing that this intervention was helpful, she repeatedly provided the same help to each mini-class, but without any more referring to the paper-and-pencil environment. Instead, her help took the form of a procedural aid, directly followed by a procedural instrumental handling aid, as in the following extract:

Clara: what do we have to do to draw a circle with diameter $\mathrm{AB}$ ?

Julia: the midpoint.

Clara: and to find the center, what should you do if you have the diameter?

Julia: the midpoint.

Clara: so, for this you click on the midpoint icon and designate the segment.

We note here that, like Daisy, Clara spent 10 min giving the same help to each group, and did not take the opportunity to shift from individual to collective assistance.

A second difficulty students encountered was to measure the angle AMB. GeoGebra can display the measure of an angle, without having to draw it, and that was what some students did. However, it is essential to visualize the angle AMB to understand the expected conjecture. Observing the screen of some groups, Clara provided instrumental handling aids, as she helped her students to draw the sides of the angle, but used a justification more suited to a paper-and-pencil environment: "you have to draw the sides of the angle, because it makes it easier to measure it". 
This extract illustrates a feature that has already been noted in classrooms of teachers who do not use DT on a regular basis. They tend to adapt a paper-and-pencil task to the technological environment, and do not take account of the fact that the software environment could interfere with the student's mathematical activity (Abboud-Blanchard, 2014). As she became aware of the phenomenon, Clara provided procedural assistance until her students could return to the planned cognitive route, managing this tension on-the-spot. However, while with a robust construction, the search for evidence is often apparent, Clara's students were distracted from the task of finding a proof.

Clara's case is an illustration of a situation that is frequently observed when teachers switch from traditional environments to technological ones. She expected her students to be able to make the link with what they could already do with paper-and-pencil. At the same time, she saw drawing the circle of diameter $\mathrm{AB}$ as an intermediary task, while the main task was to observe the invariance of an angle before trying to validate their observation using a geometrical proof. In fact, for the students, the drawing sub-task constituted a difficulty in itself in the DT context, especially as the link with paper-and-pencil environment was not explicitly presented. Thus, it was up to Clara to make the link between the two environments.

These observations show that Clara was able to help her students, despite their difficulties. Two factors could have determined her actions. The first was her personal goal to encourage her students to work autonomously. The second is related to differences in how quickly different students, or groups of students, were able to complete the task. This is a situation that is regularly observed in DT-based environments and is due to differences in both the mathematical task and DT competence.

\section{Gilles: When the Diagnosis Seeks to Sustain Students' Mathematical Progress}

Like Daisy, observations from Gilles' class concern the use of Online Exercise-Bases, with grade 10 students. Gilles is a secondary school mathematics teacher who is familiar with the use of technology in the classroom. His aim, in using this digital tool, is to help students develop their elementary algebraic know-how, i.e. how to solve equation systems and write straight line equations. He expects that the approach will be beneficial for students' mathematical skills as they are autonomous, and each can progress at his or her own pace.

Gilles's case illustrates the actions of a teacher in the diagnosis phase. He is very familiar with the software and the feedback it provides. The example shows, in broad terms, how he guided interactions with mini-classes in order to develop his students' mathematical reasoning. Here, the diagnosis phase is an integral part of the targeted learning and most of the aids provided by the teacher are constructive.

The analysis of the transcripts shows, first, that apart from providing the whole class with web links to the exercises to be done, and reminding students that they could use their notebooks to do calculations, and their textbooks for help, all of his interactions with students were individual. Gilles regularly checked on each of his students; even as he moves to answer one student's request for help, he quickly checks the work of others who are nearby. He provides few handling aids; his interventions primarily consist of explaining how to switch from one exercise to another, or how to use the application syntax. When responding to a request, he diagnoses the student's progress, encouraging him/ her to structure their reasoning, before providing assistance.

Gilles: so, are you looking for the $y$-coordinate at the origin? I don't understand most of what you've done, you have to start from somewhere; you started from the coordinates of which point?

Student: of B.

Gilles: I suggest that you write down the coordinates on a piece of paper so that you have them in front of you if you need them, then you apply your formula so you don't have to write it down and read these things written on the screen at the same time. Avoid doing two things at once, in general. 
After this exchange, Gilles checks the calculation and finds the student's error. The example highlights that Gilles tries to help the student to manage working within two environments (digital and traditional) in order to avoid making mistakes due to switching from one to the other. We also find evidence of constructive aids in Gilles' interventions. In the following extract, he explains some basic notions, and advises the student to look again at what is noted in the textbook:

Gilles: You can keep your textbook open; in fact, it's a good idea to use it. So, you found $m$, you found $p$, yes, that's good. So, the equation of the straight line $y=m x+p$ (he points to the formula in the textbook), you found the values, so go ahead.

He says to another student:

Gilles: $[\ldots]$ in other words all the points on the line have coordinates that satisfy $y$ equal -1 times the $x$-coordinate plus $p$, and the points that are not on the line do not have their $y$-coordinate equal to -1 times the $x$-coordinate... that's why we leave $x$ and $y$.

You understand that $x$ and $y$ are variables, and that variables vary... $x$ and $y$ are the coordinates of the points on the line.

Here, diagnosing, while structuring and providing constructive aid are the most frequent interventions. The remainder serves to monitor progress, validate students' work, or correct calculation errors.

We note that Gilles, who is familiar with DT, is able to provide effective assistance throughout the session. The class seems to run smoothly; all students are able to work and move forward. However, the teacher is highly mathematically involved; the majority of his students cannot progress without his help. So, despite his initial goal that students should work autonomously, his presence appears essential. These findings are in contrast with the focus of Online Exercise-Bases, which are designed to be used autonomously by students. Artigue (2007) notes that teachers who use these applications often focus on mathematical processes, in contrast with the application's focus on valid answers.

\section{Results}

On the one hand, our fine-grained analyses of teachers' interventions in DT-based environments confirm and reinforce the outcomes of our previous research and, on the other hand, offer new insights into how teachers diagnose the difficulties their students encounter and help them in ways that are more or less efficient. The flexibility of our approach led us to refocus our attention on how teachers identify problems as they arise, and how they make decisions about how to respond.

First, from a pragmatic point of view, the division of the whole class into groups with each working at one computer is not intended to foster cooperative learning. Although some of our findings are in line with the results of studies of small group work, the latter address the issue of collaborative learning (Gillies \& Boyle, 2010), while here we focus on how teachers manage the complex, open dynamic situations generated by the use of DT. All four cases support the observation that collective interventions tend to disappear (Abboud-Blanchard, 2014). We interpret this phenomenon as the result of students working at different paces, and different students or groups make more or less progress in understanding the mathematical content. The teacher cannot generalize support that is given to (some) groups - whereas it could be useful to other students. A collective intervention requires a certain degree of decontextualization. This often becomes problematic in the DT context, as students have received feedback from the software that the teacher (and sometimes students themselves) did not see, making diagnosis difficult.

Turning to diagnosis, our analyses highlight that teachers encounter several types of difficulties when diagnosing their students' needs. Some technology-based tasks are not simply an implementation of routine procedures, and may reveal a hidden lack of understanding. Even if teachers are aware of students' difficulties that should have been resolved much earlier in the student's education, these issues may be difficult to identify. This is seen in Mary's interaction with Lisa, who was very confused about 
the notion of the $y$-coordinate. Such a situation is also seen in the routine exercises that Daisy gave to her students. Almost half did not understand the notions of image and pre-image; this created cognitive and temporal tension for Daisy, as she had to repeatedly explain the difference between them.

An unexpected difficulty concerns the links between a technology-based task and the corresponding paper-and-pencil version. This was the case for Clara, who gave her students the task of drawing a circle of a given diameter, which is a routine task in a paper-and-pencil context in primary school. She was surprised to find that her students found it difficult to perform this task in the dynamic geometry software and that she had to make the interplay between DT and paper-and-pencil environments explicit.

In the classroom, DT environments can reveal unexpected, hidden conceptual difficulties that teachers could not have seen in paper-and-pencil settings. In this situation, they divide the task into sub-tasks to help students focus on the core difficulty. Two approaches can be adopted based on either procedural aids (Clara's case) or constructive aids (Daisy's case). However, in other cases, the teacher decides to ignore the problem. For example, Robert and Rogalski (2005) observed a teacher who, after interacting with a student, understood the difficulty, but decided to ignore it, saying "So, I see ... but what about ..." thus returning to the planned cognitive route (p. 287).

In contrast, we observed some unexpected means that teachers used when they anticipated their students' difficulties. In Gilles' case, the teacher was able to use his diagnosis to help his students organize their work, as well as understand the mathematical notions that were the subject of the task. He used his diagnosis and interactions with students as a learning opportunity aimed at reconstructing their mathematical thinking. This could be considered as an example of scaffolding (Wood et al., 1976), in as much as it is an intervention that goes beyond simply showing the student how to perform the task and "may involve completion or even explication of a solution already partially executed by the tutee himself" (p. 98).

The four cases we analyzed also highlight the diverse approaches that teachers take to manage tensions that arise from unexpected difficulties. Clara took a pragmatic approach and used procedural aids; Daisy provided constructive aids to overcome a "classical" misconception; Gilles asked his students to think about the problem while reflecting on the procedure they used. Mary's case illustrates the issue of disturbances triggered by an unexpected misconception that the teacher seemed to overlook and, hence, not manage.

A further consideration is the conception, which seems to be widely shared by teachers, that DT environments are a way to manage heterogeneity among students, as they can work autonomously. The same argument has been put forward in the case of small group work. For example, Hofmann and Mercer (2016) found that working in small groups bolstered students' autonomy, initiative and interdependence, but teachers' interventions remained useful to help students make mathematical progress. We also observed that teachers must provide significant help to their students, although they anticipated that feedback from the software would be enough.

\section{Discussion}

The aim of this paper was to present examples of analytical tools derived from our model of teaching as managing open dynamic situations, notably when the use of digital tools introduces an additional pragmatic, dimension to the dynamics of these situations. We examined a teaching format in which students sit in small groups around a shared computer in a lab, which increases the "openness" of the situation. Our results show that this increasing complexity amplifies some uncertainties that are already present in how teachers manage standard classroom lessons. We then focused on the issue of the teachers' diagnosis and their decision-making. We adopt the perspective that the way teachers interact with students provides a window on their teaching activity—which is why our analyses 
are based on full transcripts of the studied episodes. Beyond the results presented above, here we first discuss methodological issues, and then the potential contribution to teacher education of such in-depth investigations of DT-based practices.

First, it is reasonable to ask if another research methodology could have been used. For example, we could have shown the video recordings to teachers and asked them to comment. This (somewhat classical method) would have provided an interpretative perspective from their point of view. However, such a retrospective approach (i.e. after events had taken place) would have made it difficult-if not impossible - to identify the determinants of their activity in real time, as they themselves did not know, at the time, what might have happened as a consequence of their decision. The dynamicity that is at the core of our DT-based model of teaching requires a different methodological choice. Here, we agree with Hoc and Leplat (1983) who underlined a general feature found in studies of the management of dynamic situations: post hoc analyses are strongly influenced by the actors knowing what happened next, as they are in a situation of retrodiction instead of the prediction they made in the course of action.

A second question is whether our analyses are specific to DT? In other words, do we examine aspects that are unique to digital tools, and different from aspects relating to non-digital tools? For instance, some features could be identical, as in the case of students who are asked to solve a paper-and-pencil geometry problem with a new tool such as a protractor (at grade 6 in the French curriculum). Indeed, students' marks on a piece of paper are not always sufficient to provide teachers with information on how they attempted to measure an angle. However, the piece of paper and the protractor do not supply students with any operational feedback (there is no technical dynamicity as in dynamic geometry), and teachers must observe students' work to be able to infer their actual difficulties.

Our focus is on the "ordinary" practices of teachers, who are not participating in any research project. The consistency of the mediative component presented in the Double Approach (Robert, 2008) leads us to claim that teaching practices are coherent whether or not DT are used. The latter observation is in accordance with previous research, which indicates that the use of technology acts as an amplifier, and provides researchers with greater insight into practices (Artigue, 2007). More broadly, we argue that the issue of diagnosis and decision-making is one of the principal challenges teachers face in their day-to-day use of DT, and we expect it to become a key component in their professional development.

Going further, we believe that such analyses provide insights and analytical tools that can be used in teacher education, particularly when seeking to understand what happens in the mathematics classroom, and reflecting on alternative lesson implementations. In the context of DT-based education, teacher educators often need to provide their trainees with technology-enhanced tasks and demonstrate how DT can improve students' mathematical understanding. However, educators also need to help teachers to understand their own actions and develop ways to improve their efficiency and the quality of the support they can offer to students, given the day-to-day constraints and conditions in the classroom.

Nowadays, the use of technologies in mathematics' classrooms has become widespread, and most teachers are convinced of DT ability to support students' learning. Our work is aligned with research that seeks to understand how-and when-DT can enhance the teaching and learning of mathematics (Hoyles \& Lagrange, 2010), and examines the implications for teaching practices and teacher education (Clark-Wilson et al., 2014a, b). However, many of the challenges and difficulties that teachers encounter within technology-mediated lessons remain little explored. Educators, at least in the French context, lack solutions that can help teachers overcome these difficulties and provide appropriate levers to support students' activities.

Finally, the difficulties that were observed in our study were encountered by teachers who were all experienced professionals, and who were convinced of, and familiar with, technologies' potential as 
learning tools. This raises the question of how recently qualified teachers, who already find it difficult to navigate the beginning of their career, or teachers who are unfamiliar enough with technology, would cope with this supplementary set of difficulties and uncertainties. This is an open avenue for further research.

\section{References}

Abboud, M., \& Rogalski, J. (2017). Des outils conceptuels pour analyser l'activité de l'enseignant "ordinaire" utilisant des technologies en classe. Recherches en Didactique des Mathématiques, 37/2-3, 161-216.

Abboud, M., Clark-Wilson, A., Jones, K. \& Rogalski, J. (2018). Analyzing teachers' classroom experiences of teaching with dynamic geometry environments: comparing and contrasting two approaches. Annales de didactique et de sciences cognitives, SI-2018, 93-118.

Abboud-Blanchard, M. (2014). Teachers and technologies: shared constraints, common responses. In A. Clark-Wilson, O. Robutti \& N. Sinclair (Eds.), The Mathematics Teacher in the Digital Era: An International Perspective on Technology Focused Professional Development (pp. 297-318). London: Springer.

Abboud-Blanchard, M., \& Paries, M. (2008). Etude de l'activité de l'enseignant dans une séance de géométrie dynamique au collège. In F. Vandebrouck (Ed.), La classe de mathématiques : activités des élèves et pratiques des enseignants (pp. 261-292). Toulouse : Octarès.

Abboud-Blanchard, M., Robert, A., Rogalski, J. \& Vandebrouck, F. (2017). Activity Theory in Didactics of Mathematics. Cahiers du LDAR, $n^{\circ} 18$. Eds IREM de Paris.

Artigue, M. (2007). Digital technologies: a window on theoretical issues in mathematics education. In, D. Pitta-Oantazi \& G. Philippou (eds), Proceedings of CERME 5 (pp. 68-82). Cyprus University Editions.

Balacheff, N. (1994). La transposition informatique. Note sur un nouveau problème pour la didactique. In M. Artigue (Ed.), Vingt ans de Didactique des Mathématiques en France (pp. 364-370). Grenoble: La pensée sauvage.

Clark-Wilson, A., Aldon, G., Cusi, A., Goos, M., Haspekian, M., Robutti, O., \& Thomas, M. (2014). The challenges of teaching mathematics with digital technologies-the evolving role of the teacher. In P. Liljedahl, C. Nicol, S. Oesterle, S., \& D. Allan, D. (Eds.), Proceedings of the Joint Meeting of PME 38 and PME-NA 36 (Vol.1, pp. 87- 116). Canada: Vancouver.

Clark-Wilson, A., Robutti, O. \& Sinclair, N. (eds) (2014). The Mathematics Teacher in the Digital Era: An International Perspective on Technology Focused Professional Development. London: Springer.

Dekker, R. \& Elshout-Mohr, M. (2004). Teacher Interventions Aimed at Mathematical Level Raising during Collaborative Learning. Educational Studies in Mathematics, 56, 39-65.

Drijvers, P. (2018). Empirical evidence for benefit? Reviewing quantitative research on the fuse of digital tools in mathematics education. In L. Ball, P. Drijvers, S. Ladel, H.-S. Siller, M. Tabach, \& C. Vale (Eds.), Uses of technology in primary and secondary mathematics education; tools, topics and trends (pp. 161-178). Cham: Springer International Publishing.

Drijvers, P., Doorman, M., Boon, M., Reed, H. \& Gravemeijer, K. (2010). The teacher and the tool: instrumental orchestrations in the technology-rich mathematics classroom. Educational Studies in Mathematics, 75, 213-234.

Gillies, R.M., \& Boyle, M. (2010). Teachers' reflections on cooperative learning issues of implementation. Teaching and Teacher Education, 26(4), 933-940.

Hacker, W. (1985). On some fundamentals of action regulation. In Discovery strategies in the psychology of action (pp. 63-84). London: Academic Press.

Hoc, J.-M., \& Leplat, J. (1983). Evaluation of different modalities of verbalization in a sorting task. International Journal of Man-Machine Studies, 18, 283-306.

Hofmann, R., \& Mercer, N. (2016) Teacher interventions in small group work in secondary mathematics and science lessons. Language and Education, 30:5, 400-416.

Hoyles, C. \& Lagrange, J.B. (eds.) (2010). Digital technologies and Math Education. Rethinking the terrain. The $17^{\text {th }}$ ICMI Study. New York: Springer.

Lagrange, J.-B., \& Ozdemir, E. (2009) Teacher's emergent goals in spreadsheet based lessons: Analysing the complexity of technology integration. Educational Studies in mathematics, 71(1), 65-84.

Leplat, J. (1997). Regards sur l'activité en situation de travail. Paris: PUF.

Lundberg, J., \& Johansson, B. J.E. (2020). A framework for describing interaction between human operators and autonomous, automated, and manual control systems. Cognition, Technology \& Work, https://doi.org/10.1007/s10111-02000637-w (accessed: 06 December 2020).

Monaghan, J. (2004). Teachers' activities in technology-based mathematics lessons. International Journal of Computers for Mathematical Learning, 9(3), 327-357. 
Robert, A. (2008). La double approche didactique et ergonomique pour l'analyse des pratiques d'enseignants de mathématiques. Dans F. Vandebrouck (Eds.) La classe de mathématiques : activités des élèves et pratiques des enseignants (pp. 59-68). Toulouse: Octarès.

Robert, A., \& Hache, C. (2013). Why and how to understand what is at stake in a mathematics class. In F. Vandebrouck (Ed.), Mathematics classrooms. Students' activities and teachers practices (pp. 23-73). Sense Publishers.

Robert, A., \& Rogalski, J. (2002). Le système complexe et cohérent des pratiques des enseignants de mathématiques : une double approche. La Revue canadienne de l'enseignement des sciences, des mathématiques et des technologies, 2(4), 505-528.

Robert, A., \& Rogalski, J. (2005). A cross-analysis of the mathematics teacher's activity. An example in a French 10th grade class. Educational Studies in Mathematics, 59, 269-298.

Roditi, E. (2011). Recherches sur les pratiques enseignantes en mathématiques : apport d'une intégration de diverses approches et perspectives. Habilitation à Diriger des Recherches. France : Université René Descartes.

Rogalski, J. (2003). Y a-t-il un pilote dans la classe ? Une analyse de l'activité de l'enseignant comme gestion d'un environnement dynamique ouvert. Recherches en Didactique des Mathématiques, 23(3), 343-388.

Ruthven, K. (2014). Frameworks for analysing the expertise that underpins successful integration of digital technologies into everyday teaching practice. In A. Clark-Wilson, O. Robutti \& N. Sinclair (Eds.), The Mathematics Teacher in the Digital Era: An International Perspective on Technology Focused Professional Development (pp. 373-394). London: Springer.

Tabach, M., \& Schwarz, B.B. (2017). Professional development of mathematics teachers toward the facilitation of smallgroup collaboration. Educational Studies in Mathematics, 97(3), 273-298.

Vygotsky, L. S. (1978). Mind in society: The development of higher psychological processes. Cambridge, MA: Harvard University Press.

Wood, D.J., Bruner, J.S., \& Ross, G. (1976). The role of tutoring in problem solving. Journal of Child Psychiatry and Psychology, 17, 89-100.

Publisher's Note Springer Nature remains neutral with regard to jurisdictional claims in published maps and institutional affiliations. 